\title{
NARRATIVAS EMERGENTES SOBRE LA CONSTRUCCIÓN DE PAZ INDÍGENA EN COLOMBIA: LA RESISTENCIA SENTIPENSANTE DEL PUEBLO NASA WES'X-TOLIMA*
}

\author{
Eduardo Andrés Sandoval Forero** \\ https://orcid.org/0000-0003-1659-7588 \\ José Javier Capera Figueroa*** \\ https://orcid.org/0000-0003-1823-2814
}

RECIBIDO: Marzo 2021 / ACEPTADO: Mayo 2021 / PUBLICADO: Septiembre 2021

\begin{abstract}
Como citar: Sandoval Forero, Eduardo; Capera Figueroa, José. (2021). Narrativas emergentes sobre la construcción de paz indígena en colombia: la resistencia sentipensante del pueblo nasa wes'x-tolima. Telos: revista de Estudios Interdisciplinarios en Ciencias Sociales, 23 (3), Venezuela. (Pp. 548567).

DOI: www.doi.org/10.36390/telos233.04
\end{abstract}

\section{RESUMEN}

Las diferentes violencias que afectan de forma directa e indirecta la armonía y equilibro de los pueblos indígenas en sus territorios, representan fenómenos de índole estructural y sistémico que son motivo de reflexión de los estudios de paz en perspectiva decolonizadora. Por ende, la finalidad del siguiente artículo de investigación consiste en describir las narrativas emergentes de carácter decolonial que influyen en la construcción de paz indígena en Colombia, teniendo en cuenta la experiencia de resistencia decolonial y subalterna del pueblo Nasa Wes'x - Tolima. La metodología utilizada, es la teoría fundamentada en articulación con las narrativas, voces y experiencias comunitarias provenientes del discurso oral y praxis ética liberadora del sujeto ontológico indígena (Escobar, 2016). Asimismo, la asociación de la investigación colaborativa, análisis crítico del discurso y el diálogo intersubjetivo en el marco horizontal entre el investigador y los grupos sociales. Teniendo en cuenta las propuestas teóricas-conceptuales de construcción de paz intercultural provenientes de Alonso (2010); Fontan (2013); Márquez Fernández (2018) y Sandoval \& Capera (2020a), orientadas a la cosmovisión/cosmogonía de las comunidades

\footnotetext{
* Parte del siguiente texto fue presentado en el congreso de "Diálogos Sobre La Evaluación De La Ciencia En México - Semana ClacsoConacyt de México (2020)". Se agradece la corrección de estilo de la literata Indira Henríquez.

** Doctor en Sociología. Maestro en Estudios Latinoamericanos y Antropólogo Social, Escuela Nacional de Antropología e Historia (México). Miembro de la Academia Mexicana de la Ciencia y del Sistema Nacional de Investigadores de México, nivel III. Profesor invitado de universidades de Estados Unidos, América del Sur, España e Italia. Fundador y Coordinador Académico de la Maestría y Doctorado en Educación para la Paz y la Convivencia Escolar en México. Investigador-Profesor del CIEAP, Universidad Autónoma del Estado de México. Correo electrónico: forerosandoval@gmail.com

*** Doctorante en Ciencias Sociales y Políticas de la Universidad Iberoamericana (México). Maestro en sociología política del Instituto de Investigaciones Dr. José María Luis Mora. Politólogo de la Universidad del Tolima. Analista político y columnista del periódico el Nuevo Día (Colombia) y Rebelión.org (España). Correo electrónico: caperafigueroa@gmail.com - http://josecaperafigueroa.blogspot.mxl
} 
indígenas frente a la configuración de paces, equilibrio y armonización en los territorios ancestrales al ser principios identitarios de resistencia colectiva, pacifica, no-violenta y de convivencia restaurativa-territorial (Sandoval, 2021). Uno de los resultados más importantes es la construcción de narrativas de resistencia pacífica desde la visión decolonizadora en función de las luchas, demandas, proyectos y propuestas desde abajo de orden emergentes en articulación con las luchas socioculturales, pacíficas y democráticas populares de los pueblos indios en contravía del proyecto de guerra abierta, exterminio étnico y prácticas recolonizadoras de violencia sistémica que afecta de forma radical su condición humana y de existencia indígena.

Palabras claves: Pueblos indígenas; Paz decolonial; Resistencia; pueblo Nasa Wes'x

\section{Emerging narratives on indigenous peacebuilding in Colombia: the liberating resistance the sensing/thinking of the Nasa Wes'x-Tolima community}

\section{ABSTRACT}

The different forms of violence that directly and indirectly affect the harmony and equilibrium of indigenous peoples in their territories represent structural and systemic phenomena that are the subject of reflection in peace studies from a decolonizing perspective. Therefore, the purpose of the following research article is to describe the emerging decolonial narratives that influence the construction of indigenous peace in Colombia, taking into account the experience of decolonial and subaltern resistance of the Nasa Wes'x people - Tolima. The methodology used is grounded theory in articulation with the narratives, voices, and community experiences coming from the oral discourse and liberating ethical praxis from the indigenous ontological subject (Escobar, 2016). Likewise, the collaborative research association, critical discourse analysis, and intersubjective dialogue in the horizontal framework between the researcher and social groups. Considering the theoretical-conceptual proposals of intercultural peacebuilding coming from Alonso (2010); Fontan (2013); Márquez Fernández (2018), and Sandoval \& Capera (2020a), oriented to the cosmovision/cosmogony of the indigenous communities facing the configuration of peace, balance, and harmonization in the ancestral territories as they are identity principles of collective, peaceful, non-violent resistance and restorative-territorial coexistence (Sandoval, 2021). One of the most important results is the construction of narratives of peaceful resistance from the decolonizing vision based on the struggles, demands, projects, and proposals from below of emerging order in articulation with the socio-cultural, peaceful, and democratic popular struggles of the Indian peoples against the project of open war, ethnic extermination and recolonizing practices of systemic violence that radically affects their human condition and indigenous existence

Keywords: Indigenous peoples; Decolonial peace; Resistance; Nasa Wes'x people.

\section{Introducción}

Las discusiones epistémicas generadas a finales del siglo XX, sobre la necesidad de reconocer la configuración de narrativas alternas que provienen de las luchas socioculturales de los grupos históricamente vulnerados y afectados ante las prácticas y modos de establecer un tipo de desarrollo capitalista. Los debates promovidos por grupos, movimientos y actores 
Narrativas emergentes sobre la construcción de paz indígena en colombia: la resistencia sentipensante del pueblo Nasa Wes'x-Tolima

emergentes, parte de asumir una postura crítica - política ante las formas de explotación, control y sumisión que genera los grupos hegemónicos encargados de administrar las instituciones público-privadas.

Las narrativas construidas al interior de los sectores marginados/oprimidos de la modernidad, parten de enunciar epistemes configuradas sobre las prácticas, visiones y saberes producto de la interacción entre el mundo de la vida y la experiencia cotidiana. Así pues, los discursos semióticos derivados de la descolonización señalan la necesidad de recuperar las memorias orales, voces silenciadas o invisibilizadas por la historia oficial de los grupos hegemónicos.

De esta manera, las epistemologías del sur emergen como una configuración teórica -conceptual de orden anti-hegemónica, debido a que son:

El reclamo de nuevos procesos de producción, de valorización de conocimientos válidos, científicos y no científicos, y de nuevas relaciones entre diferentes tipos de conocimiento, a partir de las prácticas de las clases y grupos sociales que han sufrido, de manera sistemática, destrucción, opresión y discriminación causadas por el capitalismo, el colonialismo y todas las naturalizaciones de la desigualdad en las que se han desdoblado (Santos, 2011, p.16).

La construcción de saberes provenientes de los grupos excluidos se caracteriza por intentar romper con las corrientes tradicionales gestadas en las discusiones de largo alcance en el campo epistémico de las ciencias sociales. Así pues, los procesos políticos desde abajo son muestra de la emergencia de conocimientos subalternos identificados con la enunciación de espacios alternativos, diversos y plurales. Los cuales representan, insumos fundamentales para la dinámica de interculturalizar las relaciones entre los diversos grupos socioculturales que coexisten en un determinado territorio en el marco del reconocimiento de lenguajes, sentires y expresiones propias de la ecología de saberes de los pueblos originarios en contacto con la madre tierra.

Las epistemologías del sur al ser un campo epistémico de carácter alternativo en relación con los paradigmas tradicionales constituidos por las escuelas clásicas de pensamiento moderno-colonial, reflejan la importancia de optar por una perspectiva intercultural crítica que sirva como plataforma para establecer diálogos inter-epistémicos enfocados a comprender la complejidad de los fenómenos, conflictos y violencias desde los estudios paz en el contexto Latinoamericano, siendo un campo emergente que permite la reconfiguración de narrativas subalternas pensadas desde el sujeto ético-político y su concepción sobre los discursos y hechos que convergen en el marco de la industria moderna-colonial de la paz y la guerra en el siglo XXI.

En efecto, el campo de acción del sujeto que apela a la necesidad de superar los estribos del poder moderno de los grupos de arriba, se instituye en la capacidad de tejer saberes teniendo en cuenta su contexto sociocultural, conflictos, discusiones, experiencias y expresiones que hacen parte del complejo identitario que emergen de grupos sociales, actores y movimientos que mencionan la necesidad de ir a contrapelo de las narrativas de la colonialidad del podersaber (Alonso \& Ramírez, 1997).

La crítica generada a las epistemes tradicionales de los estudios de paz: liberal, conservadora, directa, indirecta, estructural, negativa y positiva entre otras. Muestra una serie 
de discursos teóricos de gran relevancia que al momento de trasladar las realidades de sociedades, sectores y movimientos excluidos de la modernidad -colonialidad, responde a una serie de reflexiones estructurales enfocadas a establecer capacidades discursivas en clave de los saberes co-producidos desde abajo y en función de la Praxis ética-liberadora de los territorios en resistencia ante los actores hegemónicos de arriba, es decir la necesidad de buscar acciones cotidianas que reflejen en el lenguaje común las narrativas, prácticas y subjetividades de los actores que convergen por romper con las teorías eurocentradas y hegemónicas propias de la colonialidad del poder-saber imperativo en la región Latinoamericana.

El ejercicio de promover un tipo de democracia sustantiva ideada bajo la capacidad de cubrir las necesidades de los grupos excluidos sin caer en la retórica de los poderes facticos 0 superlativos del Estado, por esto se utilizan las formas de interacción comunitaria constituidas como iniciativas fundamentales para innovar en las prácticas, discursos y diseños de democratizar la información y ofrecer un panorama de horizontalidad en el marco de los poderes populares que co-participan en los territorios.

La concepción epistémica- política de la democracia sustantiva tiene que ver con la capacidad de agrupar las necesidades, demandas y luchas de los diversos sectores excluidos del desarrollo -institucional, para así lograr fortalecer las dimensiones internas/externas que existen en el plano de la capacidad de potencializar el desarrollo humano integral al interior de la sociedad y teniendo en cuenta las condiciones socioculturales que identifican los diversos medios, intereses y circunstancias en los territorios (Márquez-Fernández, 2008).

La posibilidad de tejer redes de solidaridad basadas en el diálogo abierto, deliberativo y horizontal en búsqueda de superar las principales problemáticas que configuran la cotidianidad de los grupos sociales excluidos (Santos, 2011). Simboliza, un ejercicio de descolonizar las estructuras de poder modernas-coloniales para dar paso a la democratización de los saberes basados en el respeto por la vida, dignidad humana y buen vivir comunitarios que contribuya a una sociedad justa, libre y pacífica en sus distintos espacios de coexistencia societal.

El sentido narrativo descolonial en el campo de la resistencia popular y ancestral de los pueblos originarios, recae en el ejercicio de superar las estructuras del capitalismo en su versión de dominación y sumisión sobre el sujeto, hasta llegar al punto de la negación de sus propias expresiones, sentires e identidades que constituyen el ethos de cualquier formas simbólica y pragmática de vida.

La educación para la paz de orden intercultural crítico, representa una apuesta de larga duración por parte de las escuelas, redes, sectores y movimientos de carácter alternativo, que apelan al ejercicio constituido de la democratización de saberes en clave a la pluralidad de saberes como punto de inflexión propi de las epistemologías del sur (Santos, 2009). En efecto, la lógica crítica de pensar en una narrativa de paz latinoamericana tiene que ver con la necesidad de superar las discusiones normativas - procedimental para dar paso a la crítica - política de las instituciones público-privadas al interior de las democracias contemporáneas que basan su ejercicio en la praxis ética de los grupos populares y/o subalternos en los territorios (Sandoval, 2013).

El paradigma emergente de los estudios de paz latinoamericanos basados en el reconocimiento de experiencias, luchas y procesos de resistencia colectiva de carácter popular, devela la concepción teórica de Fontan, sobre la tarea de ir superando las escuelas tradicionales encargadas de ejercer un status quo epistemológico sobre la paz. Así pues, la importancia de 
Narrativas emergentes sobre la construcción de paz indígena en colombia: la resistencia sentipensante del pueblo Nasa Wes'x-Tolima

reconocer que existe una maquinaria transnacional de mercantilización sobre los proyectos, acuerdos e iniciativas de paz neoliberal en donde la racionalidad del capital privado tiene mayor importancia que las iniciativas comunitarias basadas en la cultura de las paces en contravía de las expresiones de dominación y violencia estructural (Fontan, 2013).

El esquema de reconocer los vacíos históricos generados por los grupos tradicionales encargados de control/administrar las instituciones público-privadas, representa una muestra de la colonialidad del poder-saber en dónde los grupos hegemónicos y élites que habitan en los territorios imponen modos de violencia estructural y diseños de dominación basados en la manipulación de los procesos de deliberación del sujeto, lo que conlleva a la visibilización de las narrativas del despojo, violencia, masacre y barbarie inmersa en el tipo de democracia procedimental y normativa que no garantiza las mínimas condiciones de desarrollo humano para los grupos oprimidos (Sandoval, 2013).

La pérdida de capacidad de cohesión político-social por parte de las democracias contemporáneas en Latinoamérica, devela lo expuesto por el politólogo Yascha Mounk cuando analiza el sentido iliberal de los regímenes democráticos, es decir, las contradicciones que existen en los grupos que administran los poderes institucionales, al no lograr dar soluciones reales a las demandas de los ciudadanos y carecer de medios, rutas y estructuras para hacer peso a las expresiones autoritarias, clientelares y corruptas constituidas en el marco de la acción colectiva de la política moderna-burocrática (Márquez Fernández, 2018).

De esta forma, las expresiones de paz interculturales y de abajo constituidas por los grupos en resistencia al capitalismo, conlleva a la configuración de las contradicciones de los sectores paraestatales/militares, guerrilleros y delincuencia en común/organizada que al paso del tiempo se han apoderado de las instituciones público-privado conllevado a establecer narrativas de pacificación de orden negativo/positivo en donde los conflictos son resultado de la incapacidad de concretar acciones reales encausadas a la resolución y medicación de situaciones de convivencia comunitaria.

La concepción de la génesis narrativa de los conflictos consiste en la posibilidad de asumir los procesos de contradicciones y avances propios de la condición humana, en efecto, la necesidad de conocer desde adentro la posibilidad de ofrecer alternativas a las diferencias sustanciales y/o radicales del sujeto frente a su realidad inmediata en sociedad, implica la posibilidad de superar las diferencias de forma dialógica abierta, directa y horizontal en función de la re-solución de los conflicto de forma individual y colectivo en los distintos escenarios comunitarios. Por ende, la capacidad de analizar los conflictos como parte esencial de la condición humana.

En el plano metodológico el uso del método cualitativo en interacción con la teoría fundamentada como marco metodológico, se evidenciaron la recolección de 40 documentos científicos entre ellos artículos, libros, ponencias, tesis de investigación y textos académicos vinculados con el repositorio de los estudios de paz en perspectiva descolonial, teniendo en cuenta el caso del pueblo indígena Nasa Wes'x. Asimismo, las categorías implementadas para la sistematización y análisis crítico del contenido de los materiales fueron: pueblos indígenas en Colombia, paz decolonial, resistencia popular y los archivos propios de las comunidades Nasa Wes'x. 
En la dimensión teórico-metodológica de la teoría fundada/anclada, se vincularon las oralidades/testimonios de actores en calidad de gobernador/as indígenas que conforman el resguardo Nasa Wes'x. Dicho enlace fue de gran importancia para excluir elementos novinculantes de la presente investigación en materia de la justicia, educación, salud y medicina ancestral entre otros, aunque son temáticas esenciales para futuras reflexiones en este caso era de gran estimación conocer desde adentro la narrativa oral en diálogo horizontal con actores que convergen en la comunidad indígena y su respectivo entorno sociocultural.

En donde la escucha, observación y capacidad de deliberación estuvo enfocada a conocer elementos sustanciales como experiencia, cargo y participación sobre la concepción de paz étnica en el territorio ancestral. Igualmente, la relación empírica resultado de los datos mediante el diario de campo y el acercamiento a modo de etnografía observativa con altos grados de participación horizontal y deliberativa, teniendo en cuenta las circunstancias de la pandemia covid-19, que enfrentan los integrantes de dicha comunidad indígena en el departamento del Tolima-Colombia.

Por tal motivo, la finalidad del presente artículo de investigación consiste en comprender de forma crítica la configuración de las paces gestadas por los tejidos comunales del pueblo indígena Nasa Wes'x, en el marco de la democratización de los poderes y la ecología de saberes como insumos fundamentales para superar las narrativas de los grupos tradicionales -colonizadores, dándole sentido al proceso sentipensante intercultural crítico que apela por la horizontalidad de los procesos políticos en escenarios locales, regionales e internacionales ante cualquier expresión de violencias sistémica.

La narrativa sentipensante de los pueblos indígenas en Nuestra América, se caracteriza por romper con la visión tradicional del racionalismo, positivismo y estructuralismo de los discursos científico-modernos/coloniales, para dar paso a la capacidad de reconocer la importancia de los sentires, emociones, sentidos y subjetividades de los sujetos en el marco de la configuración de acciones ético-políticas que cuestiona las diversas expresiones de violencia sistémica e institucionalizadas. Por ende, las expresiones de una propia epistemología por parte de los pueblos originarios, simboliza la capacidad de entender el mundo de significados de la vida en función del diálogo de saberes ancestrales, la ley de origen de las comunidades y la revitalización del territorio en sus diferentes acepciones socio-políticas.

\section{Aproximaciones a los estudios de paz descolonizadores}

La visión tradicional por estudiar y/o analizar el conflicto proveniente de los estudios de paz en su mayor dimensión representa una categoría asociada con la violencia. En esta perspectiva de investigación se han generado una serie de líneas alternativas construidas desde la dinámica del SUR- SUR que significa un punto medular en la geopolítica del conocimiento. Así pues, la paz como un tema de investigación ha sido teorizado desde dos visiones centrales la de corte eurocéntrico y la alternativa que propone contextualizar los temas a partir de un enfoque Latinoamericano.

La compleja tarea de seguir avanzando en la construcción de teorías que permitan pensar e innovar los paradigmas al interior de las ciencias, responde a la lógica de conceptualizar desde la experiencia intersubjetiva, las contradicciones de la realidad y la praxis del sujeto en su determinado tiempo/espacio. Así pues, reflexionar sobre un método, una teoría o una escuela de pensamiento que tenga la capacidad de canalizar la dimensión epistémica de 
Narrativas emergentes sobre la construcción de paz indígena en colombia: la resistencia sentipensante del pueblo Nasa Wes'x-Tolima

los estudios de paz en el marco de una perspectiva Latinoamericana, simboliza un reto de larga duración.

De esta manera, la sociología política Latinoamericana representa una interdisciplina del conocimiento entre la ciencia política y la sociología, que tiene la capacidad de articular métodos y metodologías para explicar, comprender o interpretar los fenómenos sociales de nuestra época, siendo el Estado, la sociedad civil, los actores sociales, las instituciones, los movimientos sociales y las organizaciones político- sociales, encargadas de establecer una agenda en el marco de demandas concretas en aspectos como la paz, la violencia, el conflicto, la corrupción, la lucha social y el poder político entre otros (Sandoval E. , 2021).

La lógica analítica y epistémica de la sociología política, se caracteriza por realizar análisis sobre los sistemas sociales y políticos, teniendo en cuenta la acción de los actores al interior del Estado, lo que implica todo un ejercicio de reflexividad frente a la dinámica formal e informal que existe al interior de la sociedad civil, siendo un referente que permite construir teorías que tenga la capacidad de comprender escenarios conflictos en donde la violencia, el despojo y la exclusión hacen parte de la emergencia de los discursos contra-hegemónicos de construir la paz desde la praxis liberadora de los actores en su respectiva comunidad (MárquezFernández, 2008)

Sin embargo, es de gran relevancia la construcción de puntos epistémico en donde se apueste por superar la dependencia y reduccionismo teórico-conceptual, dando el salto a corrientes alternas pensadas desde la condición intersubjetiva de los actores. Lo que demuestra concebir la sociología política descolonizadora como un campo epistémico coherente con fenómenos como la paz, la violencia y el conflicto en las sociedades modernas. La capacidad de articular discursos, narrativas y teorías bajo la condición de un hibrido interdisciplinario, refleja el conjunto de variables, datos, conceptos, teorías, categorías y métodos que constituyen la dimensión epistémica de la sociología política (Sartori, 1969).

La capacidad de orientar temáticas y enfoques desde la concepción de la sociología política, representa la necesidad de reflexionar sobre aspectos concretos que instituyen los debates del Estado, la sociedad civil, las instituciones, las élites, los poderes populares y políticos entre otros. Así pues, plantear una perspectiva de la sociología política de la paz, tiene que ver con una iniciativa epistémica y teórica que cuestiona los enfoques tradicionales (marxista, empírica, instrumentalista, funcional e institucional) (Oyhandy, 2010), para dar el salto a corrientes subalternas inmersas en los discursos de la descolonización del saber (Santos, 2010).

La base teórica de la sociología política en el análisis de dimensiones como lo social, lo político, la política, lo cultural y la subjetividad entre otras, se configura como un sendero que permite la teorización de los objetos/sujetos de estudios propios de la investigación social (Strauss \& Corbin, 2016). A su vez, emerge una corriente subalterna que cuestiona las estructuras cerradas/tradicionales de este campo del conocimiento, en donde el análisis de aspectos como las relaciones de poder, la correlación de fuerzas, la autoridad, el gobierno, los actores sociales y los movimientos se articulan como temáticas acordes a las propiedades ontológicas de la sociología de la política.

La narrativa subalterna de los pueblos indígenas en la construcción de paz propia, responde a su lucha por la organización desde abajo basadas en las necesidades reales que 
constituyen el sentipensar y sentiemociones de la tierra. Por ello, la alteridad de reconocer al otro como un sujeto que actúa y piensa conforme a sus propios medios e intereses, siendo un aspecto de gran vitalidad en la constitución de narrativas epistémicas desde la condición de resistencia colectiva del sujeto indígena en los territorios ancestrales.

Dicha corriente alterna enfocada a re-pensar los campos analíticos del conocimiento que constituyen la sociología política ha logrado establecer una discusión al interior del espacio académico, que establece una ecología de saberes que asume un diálogo abierto e intersubjetivo con las comunidades, pueblos y movimientos sub-alternos en donde la interacción se plantea en el marco de una horizontalidad del conocimiento y una reflexión en el marco de los estudios descoloniales (Walsh, Schiwy, \& Castro-Gómez, 2009). Así pues, adquiere relevancia la paz como tema, problema y fenómeno de investigación, a partir de una dimensión descolonizadora de la intersección entre la ciencia política y la sociología presentes en Nuestra América.

De este modo, los aporte realizados de distinguidos investigadores vinculados a las escuelas, teorías y paradigmas de los estudios de paz como son Galtung, Vicenc Fisas, Francisco Muñoz, John Paul Lederach y Vicent Martínez entre otros, señalan que los estudios de paz son un campo de gran relevancia en el mundo de las ciencias sociales dado la capacidad de problematizar categorías como son el conflicto, el post-conflicto, la resolución, la mediación y la construcción de paz en medio de ambientes hostiles y constante tipo de violencia (simbólica, familiar, ambiental, armada, política (Galtung, 2003).

Las discusiones de esta serie de teóricos se incorporan en la dimensión de los estudios de paz liberales/eurocéntricos, los cuales reconoce la paz como un proceso de construcción desde la ciudadanía e intervención del Estado, siendo una corriente que articula las instituciones, la sociedad civil y el sector privado en el marco de aplicar procesos para la resolución de los conflictos. Los estudios de paz aparecieron como una muestra por superar la geopolítica del conflicto y la guerra, intentando promover la construcción de una cultura, un modelo y un diseño de paz en donde interactúen los distintos actores sociales, económicos y políticos desde la dimensión de la resolución de los conflictos y el consenso de los actores nacionales y transicionales encargados de mediar en los distintos contextos conflictivos de la sociedad moderna (Sandoval, 2016).

Aunque dichas investigaciones son de gran relevancia en el campo de los estudios de paz, todavía no logran articular la dimensión socio-cultural de actores alternos como son: los pueblos indígenas, comunidades agrarias, afrodescendientes y populares entre otras, lo que refleja una lectura pensadas de los grupos hegemónicos siendo un factor que impulsa la reflexión de una corriente descolonizadora de la paz en el marco de las dinámicas subalternas que se gestan en Latinoamérica. Al mismo tiempo, constituye un campo epistémico en construcción que establezca un diálogo horizontal entre la sociología política, los estudios de paz y la praxis del sujeto en los territorios.

La concepción de plantear un ejercicio de paz descolonial, responde al ejercicio de reconocer las diversidades de planteamientos, acciones y rutas enfocadas a la configuración de epistemes alternativas que articulen los saberes mediante diálogos abiertos y directos por parte de los sectores no convencionales del ejercicio político moderno-colonial (Mignolo, 2004). Sin embargo, la postura de ir en contravía de los discursos oficiales no implica el desconocimiento sino la necesidad de romper con dichos velos de la colonialidad saber-poder de estos tiempos. 
Narrativas emergentes sobre la construcción de paz indígena en colombia: la resistencia sentipensante del pueblo Nasa Wes'x-Tolima

La perspectiva de los estudios de paz descolonizadores parte de los antecedentes provenientes de los grupos sociales de abajo, aquí las experiencias de las comunidades eclesiales de base, la resistencia colectiva y milenaria de los pueblos indígenas y los ejercicios de liberación de los grupos excluidos (negritudes, mujeres, migrantes, líderes sociales, estudiantes y ecologistas). En efecto, este conjunto de experiencias se manifiesta como ejercicio de resistencia ético-política en clave de liberación frente a las formas de opresión, violencia y dominación que han vivido históricamente los pueblos colonizados en Nuestra América (CECOIN ,2007).

El campo epistémico de los estudios descoloniales en clave de analizar los fenómenos de violencia, conflicto y situaciones de convivencia negativa, implica la necesidad de romper con los modelos tradicionales de evaluar, medir y validar las fuentes empíricas basadas en un tipo de conocimiento positivista, racionalista y estructuralista, por ello, la dimensión de descolonizar los estudios de paz radica en innovar los procesos de investigación en el marco del diálogo de saberes de forma dialógica y deliberativa entre los actores que coexisten en los territorios.

La narrativa descolonizadora de la investigación en el campo de los estudios de paz, considera de gran necesidad impulsar metodologías alternativas como: colaborativas, descoloniales, acción-participación, etnopaz y asociativas entre los actores con su respectiva comunidad. El sentido político-epistémico de la paz descolonial parte de tomar distancia de los procesos estatales - burocráticos que son funcionales a los intereses de sectores partidistas, clientelares y electorales frente a la necesidad de establecer acuerdos de pacificación en las comunidades con el fin de lograr algún ambiente de percepción de no-violencia.

La ruptura epistemológica de los estudios descoloniales emerge como un acto de crítica -política a la modernidad -colonialidad en su expresión de despojo de saberes e invisibilización de las prácticas socioculturales de los pueblos, comunidades y actores en las respectivas comunidades marginadas de cualquier expresión de postdesarrollo y sumidas en la exclusión de los sistema político-partidistas cooptados por las mafias regionales. La dinámica de controlar los poderes estatales por parte de los grupos de turno, genera poluciones de violencias y expresiones de descontento generalizado hacia los más excluidos de la sociedad.

Los discursos de la descolonización de paz buscan pluralizar los enfoques de investigación, docencia e incidencia social en interacción socioculturales desde abajo, es decir se constituye en una apuesta por asumir posturas de divergencia epistémica frente a los marcos monolíticos de hacer ciencia en función del capitalismo cognitivo. Tal vez, la crítica a la paz neoliberal radica en su incapacidad de solventar las necesidades reales de los grupos excluidos, debido a que se convierte en un modelo de profundización sobre las brechas de la injusticia social (Sandoval \& Capera,2020b).

El paradigma de la paz descolonizadora señala la importancia de ofrecer espacios de escucha, memoria y oralidad sobre los testimonios negados y silenciados por los actores tradicionales. A su vez, busca hacer grietas sobre las narrativas oficiales sin desconocer sus aspectos estructurales en donde apela al sentido ético-liberador de ofrecer espacios de interacción intersubjetiva del sujeto en medio del amplio desconocimiento de temas, denuncias y necesidades integrales que conforman el corpus de luchas por parte de los actores sociales en sus territorios. 
La configuración epistemológica de los estudios de paz en clave descolonial, supone la ruptura de visiones lineales: positiva, negativa, lineal, institucional y normativa. Para así, darles sentido a las expresiones de paces horizontales, descoloniales, etnografía de paz y acciónparticipación como formas de interacción de lenguaje orientadas a la resignificación del sentipensar y hacer las paces desde abajo y en contravía de las narrativas estatales de pacificación gubernamental, (Escobar, 2014).

La emergencia del paradigma de paz descolonial representa un punto de inflexión frente a la historia predominante de la no-violencia, acuerdos y paz duradera por parte de las élites partidistas y afines a la ideología del capitalismo en su versión neoliberal, aquí la lógica de establecer modelos político-económicos funcionales al gran capital conlleva a la pauperización de la democracia y las estructuras institucionales que reflejan altos índices de desigualdad social en los grupos sociales históricamente excluidos del desarrollo moderno-colonizador (Walsh, 2017).

Por tal motivo, descolonizar la paz transciende del discurso epistémico a la praxis ético-liberadora, sumida en el conjunto de narrativas, acciones y expresiones interculturales críticas que apelan a la crisis sistémica del capitalismo y apuestan por el buen vivir comunal, las relaciones de pervivencia en función de la vida, unidad, paces y democracias sub-alterna en la esfera pública popular. La emergencia del pensar crítico en la paz está sustentada en la capacidad de articular las prácticas intersubjetivas sumidas en las disputas por la transformación de la realidad desde las visiones integrales de los grupos en resistencia a la crisis civilizatoria (González, 1995).

La apuesta por democratizar los saberes como una estrategia por romper con el velo de la colonialidad del saber-poder, tiene que ver con la capacidad de tejer redes, espacios y grupos en común frente a temáticas como la luchas por la vida, paz y buen vivir en el territorio haciendo peso a las corrientes de pensamiento hegemónico de naturaleza estructuralista. Constituyen una serie de teorías, métodos y metodologías alternas conducentes a la articulación de saberes provenientes de los pueblos, actores y comunidades en resistencia ante la violencia sistémica del gran capital moderno-colonial (Strauss \& Corbin, 2016).

Las luchas socioculturales y liberadoras de los pueblos indígenas en Latinoamérica, representan una muestra de resistencia en medio de la diversidad de actores sistémicos, antisistémicos, naturalistas y anárquicos que interpelan las estructuras institucionales en el marco de la autodeterminación como muestra de una praxis popular de resistencia desde abajo al interior de los territorios ancestrales.

Tal como sucede con las experiencias descolonizadora del pueblo Zapatista en México, al establecer redes autonómicas de organización político-territorial basado en caracoles de resistencia subalterna e insurgencia popular sin apelar mecanismos de violencias sistémicas o reconocimiento por parte de las élites en sus comunidades (Alonso, 2010). A su vez, sin menor potencia epistémica de acción descolonial, toma fuerza la resistencia del CRIC (Comisión de Reguardo Indígenas del Cauca- Colombia), los cuales han generados rutas de organización comunitaria en medio del exterminio de pueblos indígenas, la persecución del narcoestado y la incapacidad del gobierno para canalizar las demandas sin recurrir a la fórmula tradicional de acuerdos escritos, verbalizados y dialogados que al pasar el tiempo se desvanecen y siguen siendo latentes las amplias desigualdades en dichos territorios ancestrales. 
Narrativas emergentes sobre la construcción de paz indígena en colombia: la resistencia sentipensante del pueblo Nasa Wes'x-Tolima

La lucha de las comunidades indígenas en la Amazonia en defensa de la madre tierra y la revitalización de los tejidos de paces en medio del panorama de violencia sistémica, contrabando y narcotráfico sumado a esto la incursión de actores armados legales e ilegales que afecta la armonía en los territorios. La necesidad de fortalecer los procesos de organización en los auto-gobiernos étnicos, representa un proceso de larga duración enfocado a promover la concepción de sustentabilidad política en contravía de los imaginarios provenientes de la sociedad mercantilizado y funcional al sistema mundo-capitalista (Sínodo Panamazónico, 2019).

Al mismo tiempo, la experiencia de actores sociales que han sido víctimas de las dinámicas de manipulación, explotación y control por parte de los grupos tradicionales reproductores de la modernidad-colonialidad, implica generar formas autoritarias de sumisión basadas en unas de las principales industrias del mundo que es la miseria. El sentido de asumir que la paz descolonial, responde a una postura crítica-propositiva basada en la capacidad de potencializar los procesos de trabajo comunal en el marco de las relaciones socio-políticas en función de la democratización de los saberes.

Las epistemes alternativas construidas por los grupos subalternos en el Sur global, se caracterizan por visibilizar las experiencias colectivas, populares y territoriales emprendidas por los sectores excluidos o víctimas de las formas de colonización del poder moderno-capitalista (Santos, 2009). En este sentido, la lucha de liberación de la madre tierra por parte de los pueblos originarios, la resistencia territorial emanada de los campesinos y el llamado a romper con los imaginarios racistas/sexista proclamado por las comunidades afro/negras son muestras de prácticas descolonizadoras construidas en medio de la crisis civilizatoria (Gabriel \& López y Rivas, 2005).

El llamado a superar los imaginarios colonizadores promotores de lenguajes, acciones y contextos violentos o conflictos, tiene que ver con la capacidad de desarrollar dinámicas de resolución de conflictos encaminadas a la superar los escollos impulsados por los sujetos colonizados y sectores hegemónicos encargados de reproducir los intereses funcionales de la modernidad -colonialidad.

La iniciativa de descolonizar la paz pretende ir más allá de las narrativas oficiales de este campo de investigación en las ciencias sociales en Latinoamérica, basadas en la necesidad de reconocer las discusiones sub-alternas sustentadas en el reconocimiento de los fenómenos silenciados producto de la insurrección epistemológica proveniente de los pueblos en movimiento. Por ello, la tarea de hacer grietas a las diversas situaciones de injustica social, política y económica se constituye en un dilema por parte de los sectores subalternos de la historia contemporánea.

La lucha sociocultural de los pueblos originarios ha servido como plataforma por descolonizar los esquemas de hacer política desde las comunidades, sin caer en la retórica tradicional de control político-burocrático propio de las mafias y grupos del poder institucionalidad en la sociedad moderna-colonial. La lógica por superar los esquemas tradicionales e impuestos por los imaginarios de grupos de poder, los cuales desconocen las demandas, luchas, sentires y denuncias colectivas de las organizaciones étnicas, representa un punto de inflexión enfocado a repensar la democracia y formas de gobierno más horizontales frente a un proyecto de Estado en una determinada nación. 
La crisis estructural que presentan las instituciones sociales en esta época, devela las paradojas situaciones entre el llamado anunciar una realidad llena de esperanza en medio del desconsuelo de las violencias. Así pues, la necesidad de lograr canalizar acciones concretar que sirvan como insumo para promover escenarios de pacificación, no-violencia y participación democrática de orden popular orientados a la construcción de narrativas de liberación teniendo en cuenta la crisis de pensamiento propio de la colonialidad del saber-poder en el sistema mundo moderno-colonial (Gutiérrez, 1975).

El reconocimiento del conjunto de teorías, métodos y metodología basadas en marcos teóricos alternativos como son los estudios de paz en clave intercultural y descolonial, simbolizan una serie de rupturas frente a las corrientes tradicionales de hacer ciencia en función de los cánones, requisitos y condiciones normativas propias de las instituciones de educación reglamentadas bajo los principios de un tipo de ciencia funcional a los interés del mercado sin lograr aportar elementos concretos para la resolución de los conflictos sistémicos generadores de situaciones de violencia generalizada ( Sandoval,2018).

\section{La narrativa colonizadora - descolonizadora de paz Nasa Wes'x- Tolima}

La posibilidad de establecer acuerdos basados en el diálogo abierto en función de superar las problemáticas que atenta contra los planes de vida en los pueblos originarios, tiene que ver con la concepción de los principios autonómicos de paz, unidad, autonomía y cultura constituidos en formas de hacer política desde abajo. Así pues, la perspectiva comunal sumidas en las narrativas del buen vivir, pacificación popular y dinámicas de resistencia basadas en la revitalización de la lengua al interior de los territorios ancestrales.

La paz descolonial representa un proyecto de orden epistémico alternativo basado en la necesidad de reconocer las experiencias y/o casos aislados por la historia oficial de los grupos tradicionales. Precisamente, la apuesta consiste en interactuar de forma horizontal con el sentir, hacer y la praxis ético-política de los pueblos, comunidades, movimientos y sectores que apelan al principio del buen vivir, vida, unidad, cultura, equidad y liberación desde los territorios en movimientos.

El punto de enunciación de los pueblos en movimiento, radica en la capacidad de constituir una democracia de orden participativa, sustantiva y horizontal que permita la resolución de los conflictos que afectan el equilibro entre actores socioculturales. En el campo de lo político, se apela al fundamento de configurar diseños comunitarios que rediman la crisis civilizatoria que afecta de forma radical la existencia humana en los territorios (Escobar, 2016).

La situación de paz territorial constituida por el pueblo indígena Nasa Wes'x en Gaitania - Tolima, se caracteriza por apelar al sentido de la vida antes que cualquier expresión o táctica de guerra abierta y directa contra la comunidad en el territorio. Por ello,

después de un año de diálogos, el sueño de la paz comenzó a ser realidad.

El 26 de julio de 1996, 50 indígenas en representación de la comunidad Nasa Wes'x se subieron a una chiva, se vistieron con uniformes deportivos y llevaron balones de fútbol, para pasar desapercibidos y llegar sin problemas hasta la vereda La Esmeralda, de Planadas, donde, en compañía de Maya Moschart, de la Cruz Roja Internacional, y monseñor José Luis Serna, firmaron el pacto de paz. Desde el mismo día quedaron atrás odios, deseos de venganza y rencor. Ninguno de los 600 niños y adolescentes que habitan 
Narrativas emergentes sobre la construcción de paz indígena en colombia: la resistencia sentipensante del pueblo Nasa Wes'x-Tolima

las ocho veredas conoce de cerca la violencia. Han llorado la partida de familiares 0 amigos, fallecidos por vejez 0 enfermedad, pero no saben de lágrimas, de soledad, ni de la angustia que provoca el terror de la guerra. Escuchan en sus clases de historia los relatos de profesores, y en sus casas a los protagonistas de un conflicto con las Farc que no desean repetir porque les dejó cientos de viudas y huérfanos (Garzón, 2015, p.1).

El proceso de negociación con la guerrilla tradicional de orden colonial las Farc, se sustentó en la necesidad de establecer un escenario de confianza dialógica que permitiera avanzar en medio de las amplias diferencias, desconfianza y falta de credibilidad por parte de la subversión y los impases de violencias estructural de los indígenas manipulados por las fuerzas militares en el territorio, asimismo la concepción política - ideológica de esta experiencia de paz, responde a la capacidad de materializar diálogos horizontales que permitiera la superación de los sucesos negativos/positivos de un conflicto que puso a los pueblos originarios en medio de una guerra abierta entre los grupos al margen de la ley, las fuerzas paraestatales e institucionales colombianas( Molano, 2015).

La cosmovisión del pueblo indígena Nasa Wes'x de promover un acuerdo de paz territorial sin caer en la retórica de negociación y consenso de los grupos tradicionales. El sentir de asumir la superación de los espíritus de la muerte para dar paso al buen vivir de la pacificación en medio de la incapacidad de lograr consensos abiertos y estructurales, representa la evidencia que la paz responde a un sentipensar y praxis integral de defensa de la vida en medio de cualquier expresión de violencia estructura y reproducción del orden moderno-colonial del Estado capitalista y la sociedad neoliberal.

La propuesta de constituir el fortalecimiento de los tejidos de paz como muestra de solidaridad en medio de la crisis de pensamiento, implica la necesidad de superar las formas tradicionales de ejercer el poder moderno en función de los intereses de actores tradicionales. Los medios de configuración de paces sumidas en las estructuras no institucionales de paz, permitió impulsar formas de comunicación directas sin la intermediación con otros sectores que generarían discordia entre los espíritus negativos propios de conflictos armado el territorio ancestral (Caviedes, 2007)

La narrativa critica - política que promovieron los Nasa Wes'x en su concepción de constitución de paces territoriales basada en la autodeterminación de la cosmovisión que representa el sentir, hacer y pensar de la pacificación comunal. Aquí las expresiones simbólicas de rechazar, las voces de las mujeres y los actos de superar la visión negativa del conflicto armado, implico superar las diferencias sustanciales para dar paso a la posibilidad de un diálogo que permita el reconocimiento, olvido y perdón entre la comunidad y la guerrilla de las Farc, siendo una experiencia de largos años que ha puesto en controversia la lógica oficial de los sectores tradicionales que se viene avanzando en la agenda del postconflicto entre el gobierno nacional y las Farc-ep propia de un acuerdo de paz moderno-colonizador ( Guzmán,2016).

La importancia de comprender el acuerdo de paz del pueblo Indígena Nasa Wes'x, consiste en la capacidad de asimilar los elementos descoloniales que existen en un acuerdo gestado en el territorio y desde abajo, teniendo en cuenta la presión del Estado, el desconocimiento de las instituciones público-privadas y la desconfianza con las Farc-ep. 
Situación que despertaría la narrativa de un modelo de pacificación neoliberal - institucional o la emergencia de procesos de resistencia territorial que contribuyen al análisis sobre los límites, avances y contradicciones del proceso de pacificación propio del pueblo indígena Nasa Wes'x, (Barros \& Padilla, 2017).

La historia de violencia interna/externa que ha vivido la comunidad indígena Nasa Wes'x en su proceso histórico al vivir la experiencia de migraciones locales producto de la violencia bipartidistas entre los bandos político-partidistas: liberales y conservadores, para Guzmán, Fals Borda \& Umaña, (2005). Sumado a esto la presencia de grupos guerrilleros colonizados y funcionales a la racionalidad instrumenta, los cuales ejercieron sistemas de exterminio a los y las líderes étnicos que se opusieron a las formas de luchas, militarización y manipulación ideológica producto del interés de los sectores socio-político inmersos en la colonialidad del poder-saber (Lander,2000).

Las versiones orales descritas por los líderes indígenas en los años 80 del siglo $\mathrm{xx}$, señalan la travesía territorial que vivieron los mayores, sabios y sabedoras de la comunidad Nasa Wes'x, los cuales tuvieron que dejar sus tierras producto de la violencia armada y persecución ideológica al no sumarse a las líneas de los sectores gamonales, partidistas y guerrilleros sería muestra de las represarías que originarios el conflicto cívico - armado entre el pueblo indígena Paeces y los sectores tradicionales, criminales y mafiosos que hacen presencia conflictiva en el territorio.

En este sentido, las luchas socioculturales en defensa de la vida, paz y territorio liderada por las autoridades ancestrales al interior del resguardo de la comunidad Nasa Wes'x, representa un hito de una experiencia de paz descolonial y colonizadoras. La primera, debido a la ruptura que tomaron de forma radical ante las autoridades público-privadas frente a la necesidad de establecer un acuerdo de paz entre la comunidad indígena con la guerrilla de las Farc-ep en 1996 en medio de la política de exterminio racial, cultural e identitario ejercida por los grupos autoridades de aquella época (Villarraga ,2012).

La cosmogonía que configuran las raíces del pensamiento Nasa Wes'x por parte de los fundadores del reguardo. Menciona el principio de la unidad, paz y buen vivir teniendo en cuenta las diversas complejidades, diferencias y situaciones problemáticas que enfrente la comunidad en su diario vivir. Aunque, la pervivencia de la lengua, cultura y valores milenarios se convierte en un gran insumo para establecer formas de comunicación que sirviera como estrategia de lucha subalterna para hacerle frente a las situaciones de violencia sistémica en el territorio.

El proceso de resistencia territorial generado por la comunidad Nasa Wes'x frente a los imaginarios de violencias bélica abierta y directa proveniente de la guerra de los mil días en Colombia, devela una serie de las narrativas de migraciones étnicas resultado de apostar por la pervivencia de la vida, cultura, espiritualidad y buen vivir (Guzmán, Fals Borda, \& Umaña, 2005 ). Los daños colaterales producto de las formas de inclusión del gobierno nacional, al promover proyectos del cuidado con los ecosistemas, fauna y flora, la soberanía alimentaria, la militarización de las tierras colectivas y el fortalecimiento de una serie de actividades agrícolas, agropecuarias y ganaderas bajo, lo cual se articula con la narrativa de hacer productivas las tierras de los pueblos originarios.

Parte de ese conjunto de estratagemas de carácter gubernamental, se constituyen en situaciones que han generado divisiones radicales frente a la concepción del auto-gobierno y 
Narrativas emergentes sobre la construcción de paz indígena en colombia: la resistencia sentipensante del pueblo Nasa Wes'x-Tolima

auto-determinación del territorio por parte de las asambleas, líderes y familiares que configuran las asambleas indígenas. La apuesta promovida por la comunidad Nasa Wes'x consiste en el fortalecimiento de los planes de vida como una ruta y programa milenario encausado a superar los dilemas, contradicciones y sucesos negativos que se presentan al interior de la administración, gerencia y organización estructural de los resguardos y cabildos en su territorio. El impacto profundo generado por los conflictos armados, políticos e ideológicos entre los grupos armados legales e ilegales con los indígenas Nasa Wes'x representa, una situación a finales del siglo XX, una hecatombe sociocultural y económica que des-configuró los tejidos comunitarios, armonización y buen vivir al interior de la comunidad. La presencia de imaginarios de violencia armada característico de los intereses de las élites partidistas y grupos afines a la racionalidad instrumental - militar fue un suceso que instituyo una especie de autodefensa indígena en el año de 1996 al interior del territorio ancestral de Gaitania - Tolima (Duque, 2014).

Parte de estas historias subyacen en las voces de los mayores y las autoridades ancestrales de aquel momento, devela la incapacidad del Estado en no garantizar las mínimas condiciones de existencia, seguridad y democracia sustantiva. Sin dejar a un lado, la poca visión político-institucional, al desconocer o no saber a ciencia cierta que connotación implica la idea del gobierno autónomo étnico en medio de sus amplias contradicciones y avance teniendo presente un panorama de exterminio racial de orden estructural en Colombia.

El avance de fortalecer iniciativas de organización comunal por parte del pueblo indígena Nasa Wes'x entra en conflicto con la concepción sistémica, racional y privada de las instituciones del Estado, debido a las relaciones de presión, reclamos e insistencia que se materializa en acciones afirmativas, colectivas y burocráticas en materia de programas de educación, salud, justicia, agricultura, ganadería, infraestructura y desarrollo territorial bajo los intereses y sintonía de los grupos hegemónicos en dicha región.

La incapacidad de lograr construir redes, tejidos y espacios integrales en donde los pueblos indígenas entre en el ejercicio de resistencia anti-sistémica, sin necesidad de depender, buscar o recibir fuentes de ingreso internacional o nacionales de ninguna índole, tal como lo ha realizado las comunidad indígenas Zapatistas en su visión de paz integral descolonial, al no caer en el juego mafiosa y clientelar del Estado que apela a establecer fuentes de financiación para así desarticular las bases, medios y estructuras que constituyen dicho movimiento subalterno indígena en su tarea de la pervivencia por el buen vivir y el fortalecimiento de los procesos identitarios en el territorio.

Por tal motivo, la situación de la comunidad Nasa Wes'x en el marco de la construcción de paz integral presenta elementos de las narrativas colonizadora y descolonizadora, lo que representa un fenómeno de investigación descolonial de gran interés para el campo de las ciencias sociales y políticas en Latinoamérica. La posibilidad de establecer los elementos que constituyen una práctica o noción de paz colonizadora y descolonizadora, refleja las amplias narrativas que convergen en el marco de la construcción de epistemes subalternas que apelan a los grupos tradicionales, pero apuestan por acciones alternativas gestadas desde abajo y en contravía de los grupos de arriba colonizadores.

La experiencia del acuerdo de paz del pueblo indígena Nasa Wes'x, representa un punto de inflexión al interior de las situaciones de concordato entre las élites partidistas enfocadas a la distribución de los poderes hegemónicos, siendo así que la narrativa 
descolonizadora instituida en la praxis ético-liberadora en gran medida de esta comunidad originaria ofrece aspectos sustanciales en los debates de la modernidad -colonialidad del saberpoder, debido a la capacidad de establecer formas de autonómicas políticas, económicas y culturales basadas en la autodeterminación del territorio, la soberanía agroecológica y el buen vivir en defensa de la vida en contravía de seguir dando gabela a los intereses de los grupos militares, políticos y guerrilleros en dicho momento.

La emergencia de paces descoloniales que coexisten en la esencia de este proceso de paz indígena Nasa Wes'x, devela la capacidad de autogestión lograda bajo formas de organización comunal que interpelan el ejercicio de regular, normativizar y controlar los conflictos de distinta índole por parte del Estado, aquí la participación, deliberación y expresiones dialógicas salen a relucir como insumos necesarios para hacer de la paz un senti-pensar que rompa con la idea racionalista de buscar consensos para fines políticos-burocráticos sino de constituir relaciones armónicas que permitan la durabilidad de lazas de diálogo y formas de noviolencia en los territorios étnicos (Houghton \& Villa, 2005).

El proceso de diálogos abiertos y directos que permitieron lograr un pacto de pacificación por la vida, unidad y defensa del territorio, muestra la necesidad que deviene de la cosmovisión Nasa Wes'x en materia de lograr superar las diferencias sustanciales con otros sectores de la población civil o cualquier grupo legal o ilegal que haga presencia en las tierras comunales, poniendo por encima el legado de la paz ante cualquier expresión de violencia directa, simbólica, sistémica o institucional, así pues la tarea de tejer redes de paz desde el sentir y el hacer fueron elementos sustanciales para la materialización de esta experiencia de paces desde abajo.

La complejidad de construir experiencias de paz en diferentes niveles: locales, municipales, regionales o nacionales representa la incapacidad de los grupos tradicionales en darle visibilidad a las demandas colectivas y expresiones generalizadas de desconecto ciudadano frente a la inviabilidad de profundizar en el proyecto recolonizador de guerra abierta funcional a los intereses geopolíticos de las transnacionales, gobiernos neoliberales e industrias criminales de orden global reproductoras del sistema mundo-capitalista (Wallerstein, 2008).

El intento de establecer espacios en común de pacificación entre actores locales que apelan al proyecto autonómico de resistencia popular en contravía de las mediaciones privadas de los grupos hegemónicos, se constituye en una pieza fundamental en la tarea epistémica de descolonizar los conflictos e impulsar espacios dialógicos de interacción, socialización y construcción de alternativas en común que discrepen de las narrativas estructuralistas promovidas por las escuelas clásicas de los estudios para la paz, propias de un modelo de investigar para la resolución de los conflictos en el plano del esquema curricular-educativo neoliberal de pacificación entre los diversos sectores de la sociedad civil en relación con los fines pragmáticos de los gobiernos corporativos.

El proceso de colonización y descolonización del proceso de paz Nasa Wes'x, radica en el análisis crítico de las experiencias, acciones e iniciativas populares de los indígenas frente a la racionalidad de la guerrilla colonizada de las Farc-ep, puesto que los esquemas de operacionalizar la guerra abierta basada en las estrategias foquitas sirvió como instrumento para desquebrajar los tejidos de unidad, buen vivir, tierras y paz de los pueblos originarios en Colombia (Monsalve, 2018). Conllevado a la profundización del exterminio étnico, territorial y espiritual de las comunidades que están viviendo intensas olas de violencia, despojo, 
Narrativas emergentes sobre la construcción de paz indígena en colombia: la resistencia sentipensante del pueblo Nasa Wes'x-Tolima

desplazamiento y silenciamiento de vidas a causa de los actores armados legales e ilegales que fisuran la armonía ancestral en sus territorios.

\section{A modo de conclusión}

La experiencia de paz descolonial y colonial construida por el pueblo indígena Nasa Wes'x, se constituye en un referente para el campo de investigación de los estudios de paz en el contexto Latinoamericano, debido a la rigurosidad epistémico-político que devela las formas de re-existencia popular que van en contravía de los medios tradicionales de ejercer el poder desde arriba. Así pues, las narrativas subalternas de los pueblos indígenas pretenden ir más allá de las lógicas de control de territorios, discriminación, indiofobia y racismo estructural generadores de modus de violencia estructural sobre las comunidades rurales en el territorio.

El enfoque de constituir un proceso descolonial que reconozca la paz como un valor comunitario, encargado de fortalecer los tejidos comunales en el marco de la vida, autonomía y buen vivir responde a la visión de paces promovida por el pueblo indígena Nasa Wes'x, siendo un antecede necesario para reconocer el diálogo de saberes, sentires y emociones emanadas de las raíces cosmogónicas de la comunidad en el territorio.

El proceso de paz autonómico de carácter indígena realizado por los Nasa Wes'x, se constituye en un marco de referencia alterno que plantea amplias reflexiones sobre las epistemes descoloniales propias de las dinámicas de los pueblos, movimientos y actores del Sur Global, en efecto, la tarea de ir más allá de las narrativas de violencia sistémica promovida por los grupos tradicionales y las guerrillas modernas-coloniales que dejan en medio del fuego directo contra el espíritu, sentir y existencia de los pueblos originarios en los territorios ancestrales.

La necesidad de reconocer la comunidad indígena Nasa Wes'x como un actor colectivo comprometido con la construcción de paz territorial desde abajo. La cual pone entre dicho la visión monolítica de ejercer estrategias de pacificación desde arriba y de forma vertical, aquí los sentipensares y sentiemociones de este pueblo originario conlleva a un plano multidimensional sobre la concepción de paz descolonial e integral que contribuye a los debates contemporáneos en esta área del conocimiento en las ciencias sociales y humanidades.

En últimas, las narrativas configuradas en el proceso de paz autónomo y con tintes coloniales y descoloniales del pueblo indígena Nasa Wes'x, representa un punto de inflexión sobre las teorías moderno-coloniales de los estudios de paz Latinoamericanos. Aquí las voces, memorias y oralidades del sujeto indígena (hombre/mujer), devela la posibilidad de romper con el velo de pacificación neoliberal del Estado colombiano para dar paso al ejercicio autonómico de resistencia territorial y buen vivir comunal en medio de la necesidad de subsistir ante la miseria gestada por la modernidad-colonialidad.

\section{Referencias bibliográficas.}

Alonso, Jorge (2010). Un sujeto a la zaga de sujetos de movimientos: pistas de indagaciones para la construcción de una teoría crítica. Utopía y Praxis Latinoamericana, 15(49), Venezuela. (pp. 35-52.) Extraído de:

Alonso, Jorge; Ramírez, Juan Manuel (1997). La democracia de los de abajo en México. La Jornada ediciones. México 
Barros, Nohora Isabel; Padilla, Santiago Andrés (2017). Sentido y memoria del acuerdo de paz Nasa Wes'x: la autonomía como posibilidad. Tesis de pregrado en Ciencia Política. Politólogo. Universidad de Ibagué. Colombia

Caviedes, Mauricio. (2007). Paz y resistencia: experiencias indígenas desde la autonomía. CECOIN - Colección Autonomía Indígena. Colombia.

CECOIN. (2007). Indígenas sin derechos: Situación de los derechos humanos de los pueblos indígenas. Ediciones Antropos Ltda. Colombia

Duque, Juliana. (2014). El único pueblo en paz de Colombia. Extraído de: http://www.semana.com/nacion/articulo/el-unico-pueblo-en-paz-de-colombia/397478$\underline{3}$

Escobar, Arturo (2014). Sentipensar con la tierra: nuevas lecturas sobre desarrollo, territorio y diferencia. Ediciones Unaula. Colombia

Escobar, Arturo. (2016). Autonomía y diseño: La realización de lo comunal. Popayán: Universidad del Cauca. Sello Editorial. Colombia

Fontan, Victoria. (2013). Descolonización de la Paz. Sello editorial Javeriana. Colombia.

Gabriel, Leo; López y Rivas, Gabriel. (2005). Autonomías indígenas en América Latina.

Nuevas formas de convivencia política. Universidad Autónoma Metropolitana Iztapalapa - Ludwig Boltzmann Institut. Plaza y Valdés, México

Galtung, Johan. (2003). Paz por medios pacíficos: paz y conflicto, desarrollo y civilización.

Bakeaz. España

Garzón, Olga Lucia (2015). Donde los indígenas y las Farc lograron vivir en paz. Extraído de El

Espectador: https://www.elespectador.com/noticias/nacional/donde-los-indigenas-yfarc-lograron-vivir-paz-articulo-559748

González, Pablo. (1995). La democracia de los de abajo y los movimientos sociales. Nueva Sociedad Nro. 136, México. (pp. 37-40.) Extraído de: https://nuso.org/articulo/lademocracia-de-los-de-abajo-y-los-movimientos-sociales/

Gutiérrez, Gustavo. (1975). Teología de la liberación. Ediciones Sígueme. España

Guzmán, Antonio (2016). Hace 20 años los Nasa Wes'x supieron perdonar con el Corazón.

Extraído de: http://www.elnuevodia.com.co/nuevodia/especiales/sucesos/291680hace-20-anos-los-nasa-we-sx-supieron-perdonar-con-el-corazon

Guzmán, German; Fals Borda, Orlando; Umaña, Eduardo (2005). La Violencia en Colombia (tomos I y II). Taurus. Bogotá.

Houghton, Juan., \& Villa, William. (2005). Violencia política contra los pueblos indígenas en

Colombia 1974-2004. Cecoin. Colombia

http://ve.scielo.org/scielo.php?script=sci_arttext\&pid=S1315-

52162010000200004\&lng=es\&nrm=iso\&tlng=es

Lander, Edgardo (2000). La colonialidad del saber: eurocentrismo y ciencias sociales.

Perspectivas latinoamericanas. Clacso. Argentina

Márquez Fernández, Álvaro. (2018). Democracia sub-alterna y estado hegemónico. crítica política desde américa latinal diálogo abierto con Álvaro B. MárquezFernández.El Pregonero- Elaleph.com S.R.L. Argentina

Márquez-Fernández, Álvaro (2008). Crisis de la episteme política del Estado moderno en América Latina. Extraído de:

http://www.corredordelasideas.org/docs/ix_encuentro/alvaro_marquez.pdf 
Narrativas emergentes sobre la construcción de paz indígena en colombia: la resistencia sentipensante del pueblo Nasa Wes'x-Tolima

Mignolo, Walter (2004). Colonialidad global, capitalismo y hegemonía epistémica. En. Sánchez, Irene; Sosa, Raquel. El debate latinoamericano, América Latina: los desafíos del pensamiento crítico. (Vol. 1) Siglo XXI. México.

Molano, Alfredo. (2015). Fragmentos de la historia del conflicto armado (1920-2010). Universidad de Antioquia. Colombia.

Monsalve, Ricardo. (2018). La guerra no deja en paz a los pueblos indígenas. Extraído de : http://www.elcolombiano.com/colombia/paz-y-derechos-humanos/la-guerra-no-dejaen-paz-a-los-pueblos-indigenas-FE9035601

Oyhandy, Angela. (2010). Sociología Política. En González, Víctor Hugo; Villareal Cantú, Eduardo. Pretextos para el Análisis Político - Disciplinas, reglas y procesos Flacso. México.

Sandoval, Eduardo (2013). Etnografía para la Paz, la Interculturalidad y los Conflictos. Revista de Ciencias Sociales 3(141), México. (pp. 11-24) Extraído de : https://www.redalyc.org/pdf/153/15329875001.pdf

Sandoval, Eduardo (2016). Educación para la paz integral - Memoria, interculturalidad y decolonialidad. ARFO Editores e Impresores LTDA. Colombia.

Sandoval, Eduardo (2018). Etnografía e investigación acción intercultural para los conflictos y la paz. Metodologías descolonizadoras. Editorial Alfonso Arena, F.P. Venezuela.

Sandoval, Eduardo, \& Capera, José. (2020a). Una aproximación a la descolonización de los estudios de paz: la experiencia intercultural y de abajo del pueblo Nasa Wes'x Tolima, Colombia. Revista Historia de la Educación Latinoamericana. 22 No. 35, Colombia. (pp.181-207).DOI https://doi.org/10.19053/01227238.11939

Sandoval, Eduardo; Capera, José. (2020b). Aproximaciones de la narrativa descolonizadora de los pueblos indígenas en movimiento en Nuestra América. En Hernández, Luis Javier. Semiótica y discursos de la descolonización. Universidad de los Andes, Red CoPaLa; Red de Pensamiento decolonial. Venezuela.

Santos, Boaventura (2010). Descolonizar el saber. Reinventar el poder. Ediciones Trilce. Uruguay.

Santos, Boaventura (2011). Introducción: las epistemologías del sur. Extraído de: http://www.boaventuradesousasantos.pt/media/INTRODUCCION_BSS.pdf

Santos, Boaventura. (2009). Epistemología del sur. Siglo XXI. México.

Sartori, Giovanni. (1969). From the sociology of politics to political sociology. Government and Opposition, 4(2), England(pp.195-214)

Sínodo Panamazónico. (2019). Instrumentum Laboris " Nuevos caminos para la iglesia y para la ecología integral". Extraído de: http://www.sinodoamazonico.va/content/sinodoamazonico/es/documentos/documento -preparatorio-para-el-sinodo-sobre-la-amazonia.html

Strauss, A., \& Corbin, J. (2016). Bases de la investigación cualitativa: técnicas y procedimientos para desarrollar la teoría fundamentada. Colombia: Universidad de Antioquia

Villarraga, Álvaro. (2012). La resistencia indígena: opción de paz. Editorial académica española. España 
Wallerstein, Immanuel. (2008). Historia y dilemas de los movimientos antisistémicos. Ediciones desde abajo. Colombia.

Walsh, Catherine. (2017). Pedagogías decoloniales: Prácticas insurgentes de resistir, (re)existir y (re)vivir. Ediciones Abya-Yala. Ecuador.

Walsh, Catherine.; Schiwy, Freya; Castro-Gómez, Santiago (2009). Indisciplinar las ciencias sociales. Geopolíticas de conocimiento y colonialidad del poder. Perspectivas desde lo andino. Ediciones Abya Yala. Ecuador. 